\section{The visual and refractive outcomes of combined and sequential penetrating keratoplasty, cataract extraction, and intraocular lens insertion}

\author{
Abstract \\ Purpose The aim of this study was to \\ investigate the visual and refractive outcome \\ of combined penetrating keratoplasty, cataract \\ extraction, and intraocular lens insertion \\ (triple procedure) compared with cataract \\ surgery following penetrating keratoplasty \\ (sequential surgery). \\ Methods Retrospective cohort study of 1256 \\ first penetrating keratoplasty for Fuchs' \\ dystrophy performed between April 1999 and \\ December 2005. In all, 1202 triple and \\ 54 sequential procedures were reviewed. \\ At 1 year, refractive outcomes were available \\ for 499 triple procedure and 26 sequential \\ surgery eyes. At 2 years, data were available for \\ 264 triple procedure and 10 sequential surgery \\ eyes. At 1 and 2 years postoperatively, graft \\ survival, best-corrected visual acuity (BCVA), \\ spherical equivalent, and cylindrical error were \\ recorded. $\chi^{2}$-Tests were used to compare visual \\ outcomes between the two groups. \\ Results At 1 year after triple procedure \\ surgery, $61 \%$ of eyes attained BCVA of $\geqslant 6 / 12$, \\ with $47 \%$ of eyes within $\pm 2 \mathrm{D}$ of emmetropia. \\ After sequential surgery, 59\% achieved BCVA \\ of $\geqslant 6 / 12$ with $67 \%$ of eyes within $\pm 2 \mathrm{D}$ of \\ emmetropia $(=0.05)$. Mean spherical \\ equivalent (MSE) at 1 and 2 years after \\ triple procedure was $+1.20 \mathrm{D}$ (SD 5.45) \\ and + 0.15 D (SD 3.58), respectively. MSE \\ following sequential surgery at 1 and 2 years \\ was $+0.08 \mathrm{D}$ (SD 3.06) and $-1.50 \mathrm{D}$ (SD 3.14), \\ respectively. Mean refractive cylinder after \\ combined surgery was $+4.16 \mathrm{D}$ (SD 5.11) and
}

DQ Nguyen', LL Mumford², MNA Jones², WJ Armitage ${ }^{3}$, SD Cook ${ }^{1}$, SB Kaye ${ }^{4}$ and DM Tole ${ }^{1}$
$+3.91 \mathrm{D}(\mathrm{SD} 2.79)$ at 1 and 2 years, respectively, compared with $+3.65 \mathrm{D}$ (SD 2.24) and +3.70 D (SD 2.06) after sequential surgery. In all, $29 \%$ of triple procedure and $27 \%$ sequential surgery eyes had an astigmatic error $\geqslant 5.0 \mathrm{D}$ after 1 year $(P=0.64)$, which increased to 34 and $30 \%$, respectively, by the second year. The 5-year graft survival was $85 \%$ in both groups. There were no differences in graft survival, visual or refractive outcomes between triple procedure, and sequential surgery techniques.

Conclusions This analysis provided no evidence of improved visual or refractive outcome after sequential surgery compared with triple procedure.

Eye (2009) 23, 1295-1301; doi:10.1038/eye.2008.301; published online 3 October 2008

Keywords: astigmatism; intraocular lens; penetrating keratoplasty; refractive outcome; triple procedure; visual acuity

\section{Introduction}

A number of patients with corneal pathology requiring penetrating keratoplasty $(\mathrm{PK})$ will also have cataracts. For such patients, the triple procedure (combined PK, cataract extraction, and intraocular lens (IOL) implantation) has been an established surgical treatment for over 30 years, ${ }^{1}$ providing good visual outcome in patients with corneal opacity and cataracts. ${ }^{2-24}$ Combined surgery is of particular benefit for
${ }^{1}$ Department of Ophthalmology, Bristol Eye Hospital, Bristol, UK

${ }^{2}$ UK Transplant, Bristol, UK

${ }^{3}$ Academic Unit of Ophthalmology, University of Bristol, Bristol Eye Hospital, Bristol, UK

${ }^{4}$ St Paul's Eye Unit, Royal Liverpool Hospital, Liverpool, UK

Correspondence: DQ Nguyen,

Bristol Eye Hospital, Lower Maudlin Street, Bristol BS1 2LX, UK Tel: + 0117928 4697; Fax: + 01179284777 . E-mail: danqbnguyen@ hotmail.com

Received: 25 June 2008 Accepted in revised form: 6 September 2008 Published online: 3 October 2008

This study has been previously presented at the Royal College of Ophthalmologists Congress, Liverpool, 2008 Financial interests: None 
patients requiring quicker visual recovery, like the elderly patients those with poor vision in their fellow eye or who have significant health problems.

An alternative technique, sequential surgery, delays cataract surgery and IOL implantation until some time after PK with a consequential delay in visual rehabilitation and the associated risks of a second operative procedure. Whether to perform a triple procedure or sequential surgery remains a debated topic. $^{25,26}$ Small comparative studies have reported superior visual and refractive outcomes with sequential surgery owing to better IOL power calculation from stable post-PK keratometry readings. ${ }^{26-30}$ Our aim was to compare triple procedure and sequential surgery, in terms of visual and refractive outcomes at 1 and 2 years after PK, using data collected routinely through the UK Transplant (UKT).

\section{Patients and methods}

We retrospectively reviewed the results of all eyes that underwent triple procedure or sequential surgery (cataract extraction and IOL insertion within 16 months of PK) between April 1999 and December 2005. Data on approximately 2500 corneal grafts per annum are routinely collected by UKT through the UK Ocular Tissue Transplant Audit. Surgeons submit data at the time of surgery, including patient details, such as age, sex, indication for transplantation, type of procedure, previous grafts and other risk factors, and the bestcorrected visual acuity (BCVA). Data, including Snellen VA and refractive outcomes (spherical equivalent and astigmatism) are also submitted at 1, 2, and 5 years postoperatively. For our analysis, postoperative data from 1 and 2 years were used. The acceptable range for visual outcome data was considered to be between 8 and 16 months and between 20 and 28 months for 1 - and 2-year visual outcomes, respectively.. Patients without complete refractive data were excluded from the analysis of refractive outcomes. All statistical analyses were performed using SAS V9.1 software (SAS institute inc., Cary, NC, USA). Kaplan-Meier survival estimates were used to determine graft survival. Differences in recipient age between the two groups were evaluated using the Kruskal-Wallis test. $\chi^{2}$-Squared tests were used to compare visual outcomes between the two groups.

\section{Results}

\section{Patient population}

The study population consisted of 1256 first PK for Fuchs' dystrophy where cataract extraction was performed either at the time of transplant or within 16 months following PK: 1202 having had a triple procedure and 54 sequential surgeries. A larger proportion of women received both triple procedure $(68 \%)$ and sequential surgeries $(57 \%)$. The median age for patients undergoing a combined triple procedure was 75, (IQ 68, 79) compared with 71 (IQ 63, 77) for those who had sequential surgery $(P=0.006)$. The 2 -year BCVA data were available for 596 triple procedures and 32 sequential surgery eyes, where BCVA had also been reported to UKT preoperatively. The 2-year refractive data were available for 264 triple procedures and 10 sequential surgery eyes.

\section{Visual acuity}

The type of surgery made no difference to postoperative BCVA with similar proportions of patients in both groups achieving a BCVA of $6 / 12$ or better: at 1 year, $61 \%$ of triple procedures and $59 \%$ of sequential surgeries achieved this level of vision and at 2 years, the respective figures were 71 and $75 \%$. Table 1 shows the median BCVA and interquartile (IQ) range along with the number of lines of improvement on the Snellen chart. At 1 year, median BCVA was 6/12 for both techniques with two lines of improvement on the Snellen chart $(\mathrm{IQ}=1$ and 4$)$. At 2 years, BCVA remained at $6 / 12$ for

Table 1 Visual acuity of patients post-penetrating keratoplasty and IOL insertion

\begin{tabular}{|c|c|c|c|c|c|c|c|}
\hline & \multirow[t]{2}{*}{$\mathrm{N}$} & \multicolumn{2}{|c|}{ Preoperative acuity } & \multicolumn{2}{|c|}{ Postoperative acuity } & \multicolumn{2}{|c|}{ Lines of change } \\
\hline & & Median & IQ range & Median & IQ range & Median & IQ range \\
\hline \multicolumn{8}{|l|}{ One year } \\
\hline Triple & 858 & $6 / 36$ & $6 / 18,6 / 60$ & $6 / 12$ & $6 / 9,6 / 18$ & 2 & $(1,4)$ \\
\hline Sequential & 46 & $6 / 24$ & $6 / 18,6 / 60$ & $6 / 12$ & $6 / 9,6 / 18$ & 2 & $(1,4)$ \\
\hline \multicolumn{8}{|l|}{ Two years } \\
\hline Triple & 596 & $6 / 36$ & $6 / 18,6 / 60$ & $6 / 12$ & $6 / 9,6 / 18$ & 3 & $(1,4)$ \\
\hline Sequential & 32 & $6 / 18$ & $6 / 18.6 / 36$ & $6 / 9$ & $6 / 6,6 / 12$ & 2 & $(1,4)$ \\
\hline
\end{tabular}

IOL, intraocular lens; IQ, interquartile range. 
triple procedures with an improvement of three lines $(\mathrm{IQ}=1$ and 4$)$ compared with a median acuity of $6 / 9$ after sequential surgery with an improvement of two lines $(\mathrm{IQ}=1$ and 4$)$ on the Snellen chart.

\section{Refraction}

Complete refractive data were available after sequential surgery for only 26 eyes at 1 year and for 10 eyes at 2 years postoperatively. One year after triple procedure, the mean spherical equivalent (MSE) was $+1.20 \mathrm{D}$ and $+0.08 \mathrm{D}$ following sequential surgery. At 2 years, the MSE was + 0.15D after triple procedure surgery and $-1.50 \mathrm{D}$ after sequential surgery. Forty-seven percent of eyes undergoing triple procedure were within $\pm 2 \mathrm{D}$ of emmetropia at 1 year with $55 \%$ achieving this by the second year. For sequential surgery, the equivalent data were $67 \%$ of eyes at 1 year $(P=0.05)$ and $50 \%$ at 2 years $(P=0.80$; Table 2$)$. Mean refractive cylinder for triple procedure and sequential surgery was $4.16 \mathrm{D}$ and $3.65 \mathrm{D}$ at 1 year, respectively, and $3.91 \mathrm{D}$ and $3.70 \mathrm{D}$ at 2 years, respectively (Table 3 ). There was little difference between the techniques in spherical equivalent and scalar cylinder at 2 years, although the paucity of refractive data in the sequential surgery group should be noted.

Table 2 Refractive outcome $( \pm 2 \mathrm{D}$ and $\pm 5 \mathrm{D}$ emmetropia) post-keratoplasty and IOL insertion

\begin{tabular}{lrccc}
\hline & $\mathrm{N}$ & MSE & $\pm 2 D$ & $\pm 5 \mathrm{D}$ \\
\hline $\begin{array}{l}\text { One year } \\
\text { Triple }\end{array}$ & 499 & $+1.20( \pm 5.45)$ & $47 \%$ & $13 \%$ \\
$\quad$ Sequential & 26 & $+0.08( \pm 3.06)$ & $67 \%$ & $7 \%$ \\
$P$-value & & & 0.05 & 0.41 \\
& & & \\
Two years & & & & \\
$\quad$ Triple & 264 & $+0.15( \pm 3.58)$ & $55 \%$ & $12 \%$ \\
$\quad$ Sequential & 10 & $-1.50( \pm 3.14)$ & $50 \%$ & $10 \%$ \\
$P$-value & & & 0.80 & 0.87 \\
\hline
\end{tabular}

D, diopters; IOL, intraocular lens; MSE, mean spherical equivalent.

Table 3 Refractive outcome $(\leqslant 2 \mathrm{D}$ and $\geqslant 5 \mathrm{D}$ cylinder $)$ post-keratoplasty and IOL insertion

\begin{tabular}{lrccc}
\hline & $\mathrm{N}$ & Mean cylinder & $\leqslant 2 D$ & $\geqslant 5 D$ \\
\hline $\begin{array}{l}\text { One year } \\
\text { Triple }\end{array}$ & 499 & $+4.16( \pm 5.11)$ & $29 \%$ & $29 \%$ \\
$\quad$ Sequential & 26 & $+3.65( \pm 2.24)$ & $35 \%$ & $27 \%$ \\
$P$-value & & & 0.64 & 0.64 \\
& & & & \\
Two years & & & & \\
$\quad$ Triple & 264 & $+3.91( \pm 2.79)$ & $35 \%$ & $34 \%$ \\
$\quad$ Sequential & 10 & $+3.70( \pm 2.06)$ & $20 \%$ & $30 \%$ \\
$P$-value & & & 0.89 & 0.89 \\
\hline
\end{tabular}

D, diopters; IOL, intraocular lens.

\section{Large ametropic errors}

Thirteen percent of triple procedure and $7 \%$ of sequential surgery eyes had a spherical equivalent greater than $\pm 5 \mathrm{D}$ at 1 year $(P=0.41)$. At 2 years, $12 \%$ of triple procedures and $10 \%$ of sequential surgery eyes had a spherical equivalent greater than $\pm 5 \mathrm{D}(P=0.87)$. Similar proportions in both groups had a postoperative astigmatic error $\geqslant 5.0 \mathrm{D}$ (Table 3 ).

\section{Graft survival}

Graft survival was $97 \%$ at 1 year in the triple group, decreasing to $93 \%$ at 2 years. The 5-year survival was $85 \%$ for both the triple procedure (95\% CI: $80-89 \%)$ and sequential surgery (95\% CI: 51-95\%) with follow-up reported for $33 \%$ of triple procedures and $38 \%$ of sequential cataract after PK group.

\section{Discussion}

Surgical management of patients with coexisting corneal pathology and cataract is commonly approached by performing combined penetrating keratoplasty, cataract extraction, and IOL insertion (triple procedure); or performing PK alone followed by cataract extraction and IOL implantation at a later operation (sequential surgery). Debate continues as to which procedure is most appropriate for patients and offers the best visual and refractive outcomes. Performing a single combined operation reduces the risks to the patients and the costs of surgery with more rapid visual rehabilitation. This is advantageous for elderly patients, those with other health problems; and patients in urgent need for improved functional vision.

\section{BCVA}

The majority of previous studies have reported similar outcomes to our results with BCVA $\geqslant 6 / 12$ in $64-85 \%$ of eyes; ${ }^{3-5,7,11,18,21-23,31,32}$ a few studies managed this acuity in only $38-46 \%$ of their patients. ${ }^{8,10,16,17,29,33}$ Serdarevic et $a l^{15}$ reported that all of their patients achieved BCVA $\geqslant 6 / 12$. They hypothesised a correlation existed between the preoperative dioptric power of peripheral recipient corneas and the postoperative central power of grafted donor corneas and used videokeratoscopic analysis of peripheral recipient corneas to determine IOL power.

The visual outcomes we found after sequential surgery are comparable with previous studies of sequential surgery. ${ }^{13,29,31,34,35}$ An advantage of sequential surgery is the ability to perform additional refractive surgery before and during the second operation. Hsiao et $a l^{13}$ and Geggel $^{34}$ reported BCVA $\geqslant 6 / 12$ in 81 and $86 \%$ from their 
series of eyes, with relaxing corneal incisions performed in 23 and $59 \%$ of patients, respectively. The potential for wide variations in refractive outcome highlights the challenge faced by the surgeon in determining the appropriate IOL power for triple procedures. To predict accurately the postoperative refractive error, reliable axial length and keratometry $(K)$ readings are essential. This can become complicated when corneal oedema or irregular corneal scarring presents abnormal $\mathrm{K}$-values, increasing the risk of unanticipated ametropic errors and significant anisometropia. ${ }^{6}$ The use of $K$ readings from the fellow eye does not provide reliable measurements. ${ }^{3}$ As post-PK corneal curvature cannot be accurately predicted in advance, ${ }^{5}$ use of multiple regression analysis with surgeon-specific values, such as average postkeratoplasty $K$ values, individualised A-constants, or fixed values for the anterior chamber depth has been advocated. ${ }^{4-6,8,12,18-21,36-38}$ However, there remains no universally accepted formula that will reliably predict an IOL power to produce emmetropia.

\section{Emmetropia}

The number of eyes achieving $\pm 2 \mathrm{D}$ emmetropia may be a more accurate reflection of visual outcome than BCVA. Our results reveal $47 \%$ of eyes undergoing triple procedure surgery were within $\pm 2 \mathrm{D}$ of emmetropia at 1 year, with $55 \%$ achieving this by the second year. This compares favourably with other studies where $39-47 \%$ of eyes attained $\pm 2 \mathrm{D}$ of emmetropia. ${ }^{27-31}$ The majority of studies evaluating triple surgery alone have shown approximately $50 \%$ of eyes achieve \pm 2 D of emmetropia, although the range of $26-95 \%$ within $\pm 2 \mathrm{D}$ of emmetropia is rather wide. $^{3-5,9,10,13,15-22,24,32,36}$ Supporters of sequential surgery highlight the potential for large ametropic errors with triple procedure surgery, arguing that IOL power can be calculated with greater accuracy when biometry is performed on a stable graft. ${ }^{26,34}$ Sixty-seven percent of eyes that underwent sequential surgery in our study were within $\pm 2 \mathrm{D}$ of emmetropia at 1 year. Only $50 \%$ of eyes recorded this at the second year, but this may have been influenced by the low numbers of eyes with complete follow-up data. Other comparative studies (Table 4) have demonstrated $48-96 \%$ of eyes to be within $\pm 2 \mathrm{D}$ of emmetropia. ${ }^{27-31}$ Geggel $^{34}$ reported $95 \%$ of eyes within $\pm 2 \mathrm{D}$ of emmetropia; but $59 \%$ of eyes in this series received astigmatic correction at the time of secondary surgery, and all graft corneal sutures had been removed in $86 \%$ of eyes. Corneal curvature has been shown to change in an unpredictable manner after suture removal, $^{39}$ and, if possible, it is preferable to remove all graft sutures before IOL power calculation for sequential surgery. Other factors that could potentially influence the refractive outcome after surgery includes the size of the graft and recipient corneal bed, trephination, and suturing technique..$^{38,40,41}$

\section{Astigmatic error}

In our study, a scalar cylinder of $\geqslant 5.0 \mathrm{D}$ was found in $29 \%$ of triple procedures and $27 \%$ of sequential surgery eyes after 1 year $(P=0.64)$ increasing to 34 and $30 \%$ of eyes, respectively, at the second year $(P=0.89)$. The increase in the scalar cylinder (astigmatism) may have resulted from the overall lower number of keratoplasties reported at the second year. Other studies have reported refractive astigmatism $\geqslant 5 \mathrm{D}$ occurring in $29-44 \%$ of eyes after triple procedure $e^{9,10,42}$ and $12 \%$ of eyes after

Table 4 Previous comparative studies of triple procedure and sequential surgery

\begin{tabular}{|c|c|c|c|c|c|c|c|c|}
\hline Study design & Design & $\begin{array}{l}\text { Number } \\
\text { of eyes }\end{array}$ & $\begin{array}{c}\text { Mean } \\
\text { follow-up } \\
\text { (monthss) }\end{array}$ & $\begin{array}{c}\text { Eyes } \pm 2 D \\
\text { of target/ } \\
\text { emmetropia }(\%)\end{array}$ & $\begin{array}{c}M S E \\
\text { (D) }\end{array}$ & $\begin{array}{c}\text { Mean } \\
\text { cylinder }\end{array}$ & $\begin{aligned} & B C V A \\
\geqslant & 6 / 12(\%)\end{aligned}$ & $\begin{array}{c}\text { Graft } \\
\text { survival }(\%)\end{array}$ \\
\hline \multirow[t]{4}{*}{ Nguyen and colleagues ${ }^{24}$} & \multirow[t]{4}{*}{ Retrospective } & $\mathrm{T}-499$ & 12 & 47 & 1.20 & 4.16 & 61 & 97 \\
\hline & & $S-26$ & & 67 & 0.08 & 3.65 & 71 & 100 \\
\hline & & $\mathrm{T}-264$ & 24 & 55 & 0.15 & 3.91 & 71 & 93 \\
\hline & & $S-10$ & & 50 & -1.50 & 3.70 & 75 & 100 \\
\hline Hayashi and Hayashi ${ }^{27}$ & Prospective & $S-23$ & & 70 & & & & \\
\hline \multirow[t]{2}{*}{ Gruenauer et $a l^{30}$} & \multirow[t]{2}{*}{ Retrospective } & $\mathrm{T}-53$ & 20.5 & 47 & -2.06 & -4.00 & & 100 \\
\hline & & $S-29$ & & 96 & 0.70 & -3.50 & & 100 \\
\hline \multirow[t]{2}{*}{ Parmar et $a l^{29}$} & \multirow[t]{2}{*}{ Retrospective } & $\mathrm{T}-28$ & 9.4 & 55 & & & 39 & 79 \\
\hline & & $S-30$ & 8.5 & 42 & & & 47 & 90 \\
\hline \multirow[t]{2}{*}{ Shimmura et $a l^{28}$} & \multirow[t]{2}{*}{ Prospective } & $\mathrm{T}-22$ & & 45 & & 3.40 & & \\
\hline & & $S-11$ & & 91 & & 2.40 & & \\
\hline Pineros et $a l^{31}$ & Retrospective & $S-23$ & & 48 & & 4.10 & 66 & \\
\hline
\end{tabular}

D, diopters; BCVA, best-corrected visual acuity; MSE, mean spherical equivalent; S, sequential surgery; $\mathrm{T}$, triple procedure surgery. 
sequential surgery. ${ }^{13}$ The comparative studies of Pineros et $a l^{31}$ revealed an astigmatic error $\geqslant 5 \mathrm{D}$ in $38 \%$ triple procedure and $42 \%$ sequential surgery eyes. In contrast, Parmar et $a l^{29}$ reported an astigmatic error $>5 \mathrm{D}$ in $23 \%$ after triple procedure surgery, but in only $9 \%$ of eyes after sequential surgery.

Sequential surgery may not be appropriate for all patients undergoing surgery, when combined surgery may allow faster visual rehabilitation compared with sequential surgery. ${ }^{5-8,12,18,21,43}$ The latter technique may not be acceptable for patients who are elderly and have other health problems, or cannot tolerate a second procedure. Newer triple procedure surgery involving endothelial keratoplasty ${ }^{4,45}$ combined with phacoemulsification and IOL implantation have demonstrated good predictability in postoperative refractive error.

\section{Graft survival}

All sequential surgery grafts remained clear at 2 years with only two failures after 5 years. The 5 -year graft survival was $85 \%$ for both groups, which compares well with published triple procedure survival rates of $69-100 \%$ over variable follow-up periods. . $^{5-11,16,18,22,23,29-33,42,46}$ The 2007 Australian Corneal Graft Registry ${ }^{47}$ reported 1- and 5-year graft survivals of 89 and $78 \%$, respectively, for triple procedure. Sequential surgery has been associated with increased graft endothelial cell count loss, and graft failure as high as $13-21 \% .^{34,35,45,48-51}$ However, improved surgical techniques and the use of intraocular viscoelastic agents may mean that secondary surgery can be performed with greater safety as suggested by a lower failure rate of $0-16 \%$ in more recent studies. ${ }^{13,29,30,34,35,43,49-52}$ Other authors have found no higher risk of graft failure from sequential surgery over triple procedure surgery, ${ }^{13,28,35,46}$ with no significant difference in the percentage of endothelial cell $\operatorname{loss}^{27,28}$ or increase in graft rejection episodes. ${ }^{31}$

\section{Limitations}

The numbers of patients involved in studies of triple procedure and sequential surgery have been generally small with study methodology differing in their inclusion or exclusion criteria, with non-uniform operating and suturing techniques with single or multiple surgeons. Consequently, any confounding factors can potentially greatly influence results and subsequent conclusions. In previous studies, reporting of postoperative results can be biased depending on whether patients with posterior segment disease were excluded from the analysis with significant impacts on BCVA outcomes. We did not exclude patients with other ocular comorbidities from our study and feel that our results of spherical and cylindrical error provide a more complete picture. Registry studies can suffer from limitations in retrospective design, with less reliable methods of data collection and the inability to control all potential variables and biases. Important long-term outcome data, however, can be obtained from registries, such as UKT, where data from a large numbers of cases can be collected and used as a quality control. These results indicate that in the United Kingdom, triple procedure surgery is much more commonly performed than sequential surgery. This consequentially limits the numbers of eyes having undergone sequential surgery and makes comparisons between the two techniques difficult. The preference for triple procedure surgery reflected in our study is supported by a survey where $92 \%$ of surgeons replied that they would perform combined surgery if a patient had coexisting corneal disease and cataract. ${ }^{53}$

\section{Conclusion}

The majority of comparative studies suggest sequential surgery results in more reliable visual and refractive outcomes over triple procedure surgery; however, sequential surgery may not be appropriate for all patients. Our study failed to show a difference in visual and refractive outcomes between triple procedure and sequential surgery, which adds value for the current clinical practice adopted by most surgeons in the United Kingdom to perform a triple procedure when a patient possesses visually symptomatic corneal disease and cataract. One of the most important considerations for both patient and surgeon is the patient's ability to regain useful vision. The faster visual rehabilitation from a single operative procedure is an advantage of triple procedure, whereas the presumed benefit of more accurate IOL selection and better visual outcome in sequential surgery was not borne out by our study.

\section{Acknowledgements}

We thank all the ophthalmic surgeons who contributed to the UK Transplant for their continued support and active participation.

\section{References}

1 Taylor DM. Keratoplasty and intraocular lenses. Ophthalmic Surg 1976; 7: 31-42.

2 Hunkeler JD, Hyde LL. The triple procedure: combined penetrating keratoplasty, extracapsular cataract extraction, and lens implantation: an expanded experience. Am Intraocular Implant Soc JK 1983; 9: 20-24. 
3 Katz HR, Forster RK. Intraocular lens calculation in combined penetrating keratoplasty, cataract extraction, and intraocular lens implantation. Ophthalmology 1985; 92: 1203-1207.

4 Binder PS. Intraocular lens powers used in the triple procedure: effect on visual acuity and refractive error. Ophthalmology 1985; 92: 1561-1566.

5 Crawford GJ, Stulting RD, Waring III GO, Van Meter WS, Wilson LA. The triple procedure: analysis of outcome, refraction, and intraocular lens power calculation. Ophthalmology 1986; 93: 817-824.

6 Binder PS. The triple procedure: refractive results: 1985 update. Ophthalmology 1986; 93: 1482-1488.

7 Meyer RF, Musch DC. Assessment of success and complications of triple procedure surgery. Am J Ophthalmol 1987; 104: 233-240.

8 Sanford DK, Klesges LM, Wood TO. Simultaneous penetrating keratoplasty, extracapsular cataract extraction, and intraocular lens implantation. J Cataract Refract Surg 1991; 17: 824-829.

9 Green M, Chow A, Apel A. Outcomes of combined penetrating keratoplasty and cataract extraction compared with penetrating keratoplasty alone. Clin Exp Ophthalmol 2007; 35: 324-329.

10 Taylor DM, Stern AL, McDonald P. The triple procedure: 2-10 year follow-up. Trans Am Ophthalmol Soc 1986; 84: 221-249.

11 Baca LS, Epstein RJ. Closed-chamber capsulorhexis for cataract extraction combined with penetrating keratoplasty. J Cataract Refract Surg 1998; 24: 581-584.

12 Pradera I, Ibrahim O, Waring III GO. Refractive results of successful penetrating keratoplasty, intraocular lens implantation with selective suture removal. Refract Corneal Surg 1989; 5: 231-239.

13 Hsaio $\mathrm{CH}$, Chen JJ, Chen PY, Chen HS. Intraocular lens implantation after penetrating keratoplasty. Cornea 2001; 20: 580-585.

14 Binder PS. Secondary intraocular lens implantation during or after corneal transplantation. Am J Ophthalmol 1985; 99: 515-520.

15 Serdarevic ON, Renard GJ, Pouliquen Y. Videokeratoscopy of recipient peripheral corneas in combined penetrating keratoplasty, cataract extraction, and lens implantation. Am J Ophthalmol 1996; 122: 29-37.

16 Davis EA, Azar DT, Jakobs FM, Stark WJ. Refractive and keratometric results after the triple procedure. Ophthalmology 1998; 105: 624-630.

17 Geerards AJM, Hassmann E, Beekhuis WH, Remeyer L, van Rij G, Rijneveld WJ. Triple procedure; analysis of outcome, refraction, and intraocular lens power calculation. Br J Ophthalmol 1997; 81: 774-777.

18 Mattax JB, McCulley JP. The effect of standardized keratoplasty technique on IOL power calculation for the triple procedure. Acta Ophthalmol Suppl 1989; 192: 24-29.

19 Viestenz A, Seitz B, Langenbucher A. Intraocular lens power prediction for triple procedures in Fuchs' dystrophy using multiple regression analysis. Acta Ophthalmol Scan 2005; 83: 312-315.

20 Djalilian AR, George JE, Doughman DJ, Holland EJ. Comparison between the refractive results of combined penetrating keratoplasty/transsclerally sutured posterior chamber lens implantation and the triple procedure. Cornea 1997; 16: 319-321.
21 Musch DC, Meyer RF. Prospective evaluation of a regression-determined formula for use in triple procedure surgery. Ophthalmology 1988; 95: 79-85.

22 Skorpik C, Menapace R, Gnad HD, Grasl M. The triple procedure results in cataract patients with corneal opacity. Ophthalmologica. 1988; 196: 1-6.

23 Kirkness CM, Cheong PY, Steele AD. Penetrating keratoplasty and cataract surgery: the advantages of an extracapsular technique combined with posterior chamber intraocular implantation. Eye 1987; 1: 557-561.

24 Das S, Langenbucher A, Jacobi C, Nguyen NX, Kruse FE, Naumann GO et al. Long-term refractive and visual outcome after penetrating keratoplasty only $v$ s the triple procedure in Fuch's dystrophy. Graefe's Arch Clin Exp Ophthalmol 2006; 244: 1089-1095.

25 Davis EA, Stark WJ. The triple procedure - is it the best approach for the patient? The triple procedure may be superior to sequential surgery (controversies). Arch Ophthalmol 2000; 118: 414-415.

26 Hamill MB. The triple procedure - is it the best approach for the patient? Sequential surgery may be the best approach for the patient (controversies). Arch Ophthalmol 2000; 118: 415-417.

27 Hayashi K, Hayashi H. Simultaneous vs sequential penetrating keratoplasty and cataract surgery. Cornea 2006; 25: 1020-1025.

28 Shimmura S, Ohashi Y, Shiroma H, Shimazaki J, Tsubota K. Corneal opacity and cataract triple procedure vs secondary approach. Cornea 2003; 22: 234-238.

29 Parmar P, Salman A, Kalavathy CM, Thomas PA, Jesudasan CA. Outcome analysis of cataract surgery following therapeutic keratoplasty. Cornea 2005; 24: 123-129.

30 Gruenauer-Kloevekorn C, Kloevekorn-Norgall K, Duncker GIW, Habermann A. Refractive error after triple and nonsimultaneous procedures: is the application of a standard constant keratometry value in IOL power calculation advisable? Acta Ophthalmol Scan 2006; 84: 679-683.

31 Pineros OE, Cohen EJ, Rapuano CJ, Laibson PR. Triple vs nonsimultaneous procedures in Fuch's dystrophy and cataract. Arch Ophthalmol 1996; 114: 525-528.

32 Busin M, Arffa RC, McDonald MB, Kaufman HE. Combined penetrating keratoplasty, extracapsular cataract extraction and posterior chamber intraocular lens implantation. Ophthalmic Surg 1987; 18: 272-275.

33 Sridhar MS, Murthy S, Bansal AK, Rao GN. Corneal triple procedure: Indications, complications, and outcomes. A developing country scenario. Cornea 2000; 19: 333-335.

34 Geggel HS. Intraocular lens implantation after penetrating keratoplasty: improved unaided visual acuity, astigmatism, and safety in patients with combined corneal disease and cataract. Ophthalmology 1990; 97: 1460-1467.

35 Nagra PK, Rapuano CJ, Laibson PR, Kunimoto DY, Kay M, Cohen EJ. Cataract extraction following penetrating keratoplasty. Cornea 2004; 23: 377-379.

36 Flowers CW, McLeod SD, McDonnell PJ, Irvine JA, Smith RE. Evaluation of intraocular lens power calculation formulas in the triple procedure. J Cataract Refract Surg 1996; 22: $116-122$.

37 Uusitalo RJ, Tarkkanen A. Outcomes of small incision cataract surgery. J Cataract Refract Surg 1998; 24: 212-221.

38 van Rij G, Waring III GO. Configuration of corneal trephine opening using five different trephines in human donor eyes. Arch Ophthalmol 1988; 106: 1228-1233. 
39 Madder TH, Yuan R, Lynn MJ, Stulting RD, Wilson LA, Waring III GO. Changes in keratometric astigmatism after suture removal more than one year after penetrating keratoplasty. Ophthalmology 1993; 100: 119-126.

40 Cohen KL, Holman RE, Tripoli NK, Kupper LL. Effect of trephine tilt on corneal button dimensions. Am J Ophthalmol 1986; 101: 722-725.

41 Jonas JB, Rank RM, Budde WM, Sauder G. Factors influencing visual outcome after penetrating keratoplasty combined with intraocular lens implantation. Eur J Ophthalmol 2003; 13: 134-138.

42 Claoué C, Ficker L, Kirkness C, Steele A. Refractive results after corneal triple procedures (PK + ECC + IOL). Eye 1993; 4: 446-451.

43 Binder PS. Intraocular lens implantation after penetrating keratoplasty. Refract Corneal Surg 1989; 5: 224-230.

44 Terry MA, Ousley PJ. In pursuit of emmetropia: spherical equivalent refraction results with deep lamellar endothelial keratoplasty (DLEK). Cornea 2003; 22: 619-626.

45 Covert DJ, Koenig SB. New Triple procedure: Descemet's stripping and automated endothelial keratoplasty combined with phacoemulsification and intraocular lens implantation. Ophthalmology 2007; 114: 1272-1277.
46 Bersudsky V, Rehany U, Rumelt S. Risk factors for failure of simultaneous penetrating keratoplasty and cataract extraction. J Cataract Refract Surg 2004; 30: 1940-1947.

47 Williams KA, Hornsby NB, Bartlett CM, Holland HK, Esterman A, Coster DJ. The Australian Corneal Graft Registry 2004 Annual Report. Snap printing: Adelaide, 2004.

48 Payant JA, Gordon LW, Vander Zwaag R, Wood TO. Cataract formation following corneal transplantation in eyes with Fuch's endothelial dystrophy. Cornea 1990; 9: 286-289.

49 Martin TP, Reed JW, Legault C, Oberfeld SM, Jacoby BG, $\mathrm{Yu}$ DD et al. Cataract formation and cataract extraction after penetrating keratoplasty. Ophthalmology 1994; 101: 113-119.

50 Stark WJ, Maumenee AE. Cataract extraction after successful penetrating keratoplasty. Am J Ophthalmol 1973; 75: 751-754.

51 Ohguro N, Matsuda M, Kinoshita S. Effects of posterior chamber implant lens implantation on the endothelium of transplanted corneas. Br J Ophthalmol 1997; 81: 1056-1059.

52 Ficker LA, Kirkness CM, Steele AD, Rice NS, Gilvarry AM. Intraocular surgery following penetrating keratoplasty: the risks and advantages. Eye 1990; 4: 693-697.

53 Burdon MA, McDonnell P. A Survey of corneal graft practice in the United Kingdom. Eye 1995; 9(Suppl): 6-12. 